\title{
Diversifikasi dan Optimasi Usahatani Terintegrasi pada Lahan Kering di Desa Musi Kecamatan Gerokgak Kabupaten Buleleng
}

\author{
Diversification and Optimization of Integrated-Farming on Dry Land in Musi \\ Village, Gerokgak District, Buleleng Regency
}

\author{
Wisno Wardana*) \\ I Wayan Budiasa \\ Ketut Suamba
}

\author{
Magister Agribisnis, Pasca Sarjana Universitas Udayana, Bali, Indonesia \\ ${ }^{*}$ Email : wisnowardana84@gmail.com
}

\begin{abstract}
The objectives of the research were (1) to analyze the gross margin of integratedfarming (2) to analyze whether farming diversification in dry land integrated farming was optimal. The sample of the research used a census sampling technique. This sampling technique uses all members of SIMANTRI 001 as a sample with a group of 20 people. The actual income analysis used is farming analysis through gross margin calculation. Optimization analysis and maximum revenue are analyzed using the linear programming (LP) method which was completed with the assist of BPLX88 software (Eastern software product, inc. 1984). The results showed that based on the results of gross margin analysis, with an average dry land area of 0.497 ha, the actual income for maize MT-1, maize MT-2, peanuts and cattle was Rp. 696,326,650 per year. Based on the results of linear programming analysis seen from the primal problem solution, it shows that the first maize (PJG1), second maize(PJG2), peanuts (PKT) and cattle (PSAPI) are cultivated on a basic or profitable basis. This shows that the 0.497 ha of land that has been used by the sample farmers contributed to obtaining the maximum income of Rp. 697,333,800 per year. Furthermore, in the dual problem solution, all land constraints per branch of farming with a land area of 9.95 ha for each plant have been used up. This shows that the land constraints of MT-1 maize, MT-2 maize, and peanuts are binding used up without any residue (slack). However, some of the constraints are not binding, this can be seen in the stock of labor in January-December which has not been used up. Based on the optimization analysis through the linear programming method with the assist of BLPXX8, it was carried out optimally, this was proven by the maximum income of Rp.697,334,000 means that there is an increase in income of Rp. $1,007,350$ (0.14\%), from the actual income during the research of Rp. 696,326,650. To increase farm income, considering that there are still workers left in farming activities, farmers are advised not to hire labor in their farming.
\end{abstract}

Keywords: optimalization, integrated-farming system, gross margin, linear programming 


\begin{abstract}
ABSTRAK
Tujuan penelitian adalah (1) menganalisis besarnya pendapatan aktual (gross margin) usahatani terintegrasi (2) menganalisis apakah diversifikasi usahatani pada usahatani terintegrasi lahan kering sudah optimal. Metode yang digunakan dalam menentukan sampel pada penilitian ini adalah teknik sensus sample. Teknik sampel ini menggunakan semua anggota SIMANTRI 001 sebagai sampel dengan anggota kelompok sebanyak 20 orang. Analisis pendapatan aktual yang dipergunakan adalah analisis usahatani melalui perhitungan gross margin. Analisis optimasi dan pendapatan maksimun dianalisis menggunakan metode linear programming (LP) yang diselesaikan dengan bantuan software BPLX88. Hasil penelitian menunjukkan bahwa berdasarkan hasil analisis gross margin, dengan rata-rata luas lahan kering sebesar 0,497 ha, diperoleh pendapatan aktual usahatani jagung MT-1, jagung MT-2, kacang tanah dan ternak sapi sebesar Rp. 696.326.650 per tahun. Berdasarkan hasil analisis linear programming yang dilihat dari primal problem solution menunjukkan jagung (PJG1), jagung (PJG2), kacang tanah (PKT) dan sapi (PSAPI) yang diusahakan bersatus basic atau profitable. Hal ini menunjukkan bahwa lahan seluas 0,497 ha telah berkontribusi dalam memperoleh pendapatan maksimum sebesar Rp. 697.333 .800 per tahun. Selanjutnya pada dual problem solution, semua kendala lahan per cabang usahatani dengan luas lahan masing-masing tanaman sebesar 9,95 ha telah habis terpakai, Hal ini menunjukkan bahwa kendala lahan jagung MT-1, jagung MT-2, dan kacang tanah berstatus binding atau habis terpakai tanpa ada sisa (slack). Namun sebagian kendala tidak bersifat binding hal ini terlihat pada stok tenaga kerja bulan Januari-Desember yang belum habis digunakan. Berdasarkan analisis optimasi melalui metode linear programming dengan bantuan BLPXX8 terselenggara dengan optimal, hal ini terbukti dengan pendapatan maksimum sebesar Rp. 697.334 .000 artinya mengalami peningakatan pendapatan sebesar Rp.1.007.350 (0,14\%), dari pendapataan aktual saat penelitiaan sebesar Rp.696.326.650.
\end{abstract}

Kata kunci: optimalisasi, sistem usahatani terintegrasi, gross margin, linear programming.

\title{
PENDAHULUAN
}

\section{Latar Belakang}

Bali merupakan daerah yang terkenal dengan industri pariwisata yang maju bahkan sampai ke mancanegara namun masih banyak penduduk yang miskin, terutama daerah pedesaan. Berdasarakan data (BPS, 2019) pada tahun 2018 tercatat 171,76 ribu penduduk miskin di Bali menurut kabupaten dan kota.

Salah satu program pemerintah untuk pembangunan pertanian dalam percepatan penanggulangan kemiskinan di Provinsi Bali adalah sistem pertanian terintergrasi (SIMANTRI). Pada tahun 2009 pemerintah Provinsi Bali telah merealisasi program SIMANTRI dengan 10 titik lokasi kegiatan, sampai tahun 2018 total secara keseluruhan SIMANTRI di Provinsi Bali terdapat 752 unit. 
Secara teknis SIMANTRI merupakan cara mengintegrasikan sektor pertanian dengan sektor pendukungnya melalui pemanfaatan sumber daya sesuai potensi masing-masing daerah baik secara vertikal maupun horizontal.

Penerapan program SIMANTRI di Desa Musi dihadapakan oleh beberapa kendala sumberdaya yang dimiliki oleh petani seperti tenaga kerja tersedia, lahan dan lain-lain. Dalam usaha untuk memperoleh pendapatan maksimal yang dihadapakan dengan sumber daya yang terbatas, maka penelitian optimasi sistem usahatani di Desa Musi Kecamatan Gerokgak perlu dilakukan dengan pendekatan programasi linear.

\section{Tujuan Penelitian}

Tujuan Penelitian adalah untuk menganalisis besarnya pendapatan aktual (gross margin) usahatani terintegrasi dan mengenalisis apakah diversifikasi usahatani pada usahatani terintegrasi lahan kering sudah optimal.

\section{METODE PENELITIAN}

Penelitian ini dilakukan pada SIMANTRI 001 pada Gapoktan Bina Karya Bakti di Desa Musi, Kecamatan Gerokgak, Kabupaten Buleleng. Metode yang digunakan dalam menentukan sampel pada penilitian ini adalah teknik sensus sample. Teknik sampel ini menggunakan semua anggota SIMANTRI 001 sebagai sampel dengan anggota kelompok sebanyak 20 orang. Data yang digunakan dalam peneilitian ini adalah data primer dan data sekunder.

Analisis pendapatan kotor yang digunakan peneliti adalah metode analisis gross margin, untuk menghitung pendapatan dianalisis dengan rumus :

$$
\mathrm{GM}=\mathrm{TR}-\mathrm{VC}
$$

Keterangan:

$\mathrm{GM}=$ Gross margin $(\mathrm{Rp})$

$\mathrm{TR}=$ Total Revenue $(\mathrm{Rp})$

$\mathrm{VC}=$ Variable Cost $(\mathrm{Rp})$

Sedangkan untuk model optimasi dan pendapatan maksimun dianalisis menggunakan metode Linear Programming (LP) yang diselesaikan dengan bantuan software BPLX88 (Eastern software product, inc. 1984).

Secara matematis, programasi linier umumnya dinyatakan sebagai berikut
a. Fungsi Tujuan ; $\mathrm{Z}=\mathrm{C}_{1} \mathrm{X}_{1}+\mathrm{C}_{2} \mathrm{X}_{2}+\ldots . . \mathrm{C}_{13} \mathrm{X}_{13}$
b. Fungsi kendala ; a11 X1 +a $12 \mathrm{X} 2+\ldots+\mathrm{a} 113 \mathrm{X} 13 \leq \mathrm{b}_{1}$
$\mathrm{a} 21 \mathrm{X} 1+\mathrm{a} 22 \mathrm{X} 2+\ldots+\mathrm{a} 213 \mathrm{X} 13 \leq \mathrm{b}_{2}$
$\mathrm{a} 31 \mathrm{X} 1+\mathrm{a} 32 \mathrm{X} 2+\ldots+\mathrm{a} 313 \mathrm{X} 13 \leq \mathrm{b}_{3}$
a26 $1 X 1+$ a26 $2 X 2+\ldots+$ a26 $13 X 13 \leq b_{26}$
c. Asumsi ; X1, X2, .. X $13, \geq 0$ 


\begin{tabular}{|c|c|c|}
\hline la & & \\
\hline $\mathrm{Z}$ & $=$ & $\begin{array}{l}\text { Nilai fungsi tujuan untuk memaksimalkan pendapatan } \\
\text { usahatani terintegrasi antara tanaman jagung MT-1, kacang } \\
\text { tanah, tanaman jagung MT-2 dan ternak sapi. }\end{array}$ \\
\hline $\mathrm{C} 1-\mathrm{C} 13$ & $=$ & kontribusi dari aktivitas terhadap nilai fungsi tujuan. \\
\hline $\mathrm{X} 1-\mathrm{X} 13$ & $=$ & $\begin{array}{l}\text { tingkat aktivitas produksi tanaman jagung MT1 (PJG1), } \\
\text { jagung MT2 (PJG2), kacang tanah(PKT), produksi sapi } \\
\text { (PSAPI) dan sewa tenaga kerja (STK) }\end{array}$ \\
\hline bI - b26 & $=$ & $\begin{array}{l}\text { jumlah maksimun dari sumberdaya yang tersedia (kendala } \\
\text { luas lahan tanaman jagung MT-1 (MLJG1), tanaman jagung } \\
\text { MT-2 (MLJG2), kacang tanah (MLKT), ternak sapi } \\
\text { (MSAPI), tenaga kerja tersedia (STK01-STK012) }\end{array}$ \\
\hline a11- a26 13 & $=$ & $\begin{array}{l}\text { jumlah unit dari sumberdaya yang diharapkan untuk } \\
\text { memproduksi per unit aktivitas }\end{array}$ \\
\hline
\end{tabular}

Penelitian ini terdiri dari tiga aktivas yaitu produksi tanaman, produksi ternak, dan sewa tenaga kerja. Semua aktivitas dan koefisien didefinisikan sebagai berikut :

a. Produksi Tanaman dan Sapi

Koefisien positif satu pada kolom produksi jagung MT-1 (PJG1), jagung MT-2 (PJG2) dan produksi kacang tanah (PKT) artinya pengurangan lahan satu hektar untuk memproduksi tanaman jagung dan kacang tanah. Koefisen postif satu pada produksi sapi mengindikasikan pengurangan satu ekor sapi. Koefisen pada baris tenaga kerja tersedia (TKT01-TKT12) dan kolom produksi sapi dan tanaman artinya jumlah TKT yang diperlukan untuk memproduksi satu ekor sapi dan satu hektar tanaman jagung dan kacang tanah.

b. Sewa Tenaga Kerja (STK)

Koefisien negatif satu pada kolom STK dan baris TKT artinya penambahan TK yang diperlukan dalam satu HOK, dengan kata lain setiap aktivitas STK satu HOK maka ada tambahan stok TKT.

c. Produksi Sapi

Koefisien positif 0,007 pada baris lahan dan kolom produksi sapi artinya berkurangnya luas lahan sapi 0,007 ha untuk satu ekor sapi yang diproduksi.

Selanjutnya pada penlitian ini terdapat kendala, masing-masing kendala dijelaskan sebagai berikut dan hubungannya dengan RHS.

a. Total luas lahan tanaman dan ternak sapi

Total luas lahan yang tersedia untuk memperoleh produksi tanaman jagung MT1, jagung MT2, kacang tanah, produksi sapi adalah 10,51 ha. nilai RHS kurang dari atau sama dengan $\leq$ mengindikasikan lahan yang digunakan bisa lebih kecil dari ketersediaan.

b. Luas lahan masing-masing tanaman dan ternak sapi

Luas lahan tanaman pada produksi jagung MT1, jagung MT2, kacang tanah dan ternak sapi masing masing diindikasikan pada nilai RHS. Hubungan lebih kecil atau sama dengan $(\leq)$ menandakan penggunaan lahan bersangkutan dapat lebih kecil dari ketersediannya.

c. Tenaga kerja tersedia

Tenaga kerja tersedia dihitung dengan tenaga kerja produktif yang aktif dalam kegiatan usahatani dalam satuan HOK. Rata-rata tenaga kerja keluarga produktif 
dalam berusahatani sebesar 2.05 orang. Jumlah tenaga kerja tersebut sama dengan 46,12 HOK per bulan dengan asumsi terdapat 30 hari kerja dalam sebulan untuk kegiatan usahatani. Sehingga total ketersediaan tenaga kerja keluarga per bulan seluruh petani sampel sebesar 922,5 HOK per bulan. nilai RHS kurang dari atau sama dengan $\leq$ menunjukan bahwa tenaga kerja yang digunakan lebih kecil dari pada tenaga kerja yang tersedia.

d. Ternak Sapi

Nilai RHS kurang dari atau sama dengan $\leq 80$ artinya ternak sapi yang dipelihara selama satu tahun maksimal 80 ekor.

\section{HASIL DAN PEMBAHASAN}

Hasil penelitian menunjukkan bahwa petani responden menggunakan tiga kali musim tanam dengan pola tanam jagung MT-1, jagung MT-2 dan kacang tanah. Musim tanam yang pertama dalam penelitan ini yaitu bulan November sampai dengan Februari petani menanam jagung, musim tanam kedua yaitu Maret sampai dengan Juni petani menaman Jagung dan musim tanam ketiga yaitu bulan Juli sampai dengan Oktober petani menanam kacang tanah. Petani memproduksi sapi sepanjang tahun dari Januari sampai dengan Desember.

Untuk mengetahui pendapatan sistem usahatani terintegrasi yang dilakukan oleh petani sampel dapat dianalisis dengan menggunakan analisis gross margin. Hasil penelitian pada SIMANTRI 001 dari 20 petani sampel menunjukkan bahwa pengunaan rata-rata lahan seluas 0,497 ha, diperoleh pendapatan rata-rata sebesar $\mathrm{Rp} 3.646 .082$ per satu siklus produksi jagung MT-1, pendapatan jagung MT-2 sebesar Rp 4.555.800, pendapatan kacang tanah sebesar Rp. 4.443.950,00, dan pendapatan rata-rata ternak sapi sebesar Rp 22,170.500 per tahun.

Untuk mengetahui usahatani terintegrasi yang dilakukan oleh petani sampel lahan kering sudah optimal dengan menggunakan analisis programasi linear dengan bantuan sofware program BLPX88 (Eastern Sofware product, Inc, 1984). Berdasarkan primal problem solution menunjukkan aktivitas jagung MT-1 (PJG1), jagung MT-2 (PJG2), kacang tanah (PKT) dan sapi (PSAPI) yang diusahakan bersatus basic atau profitable. Hal ini menunjukkan bahwa lahan seluas 0,497 ha yang digunakan petani sampel berkontribusi dalam memperoleh pendapatan maksimum sebesar Rp. 697.333 .800 per tahun. Namun tidak semua aktivitas berstatus basis pada sewa tenaga kerja. Sewa tenaga kerja bulan Februari (STK02), Maret (STK03), April (STK04), Juni (STK06), Juli (STK07), Agustus (STK08), Oktober (STK10), November (STK11) dan Desember (STK12) berstatus nonbasis maka tidak direkomendasikan menyewa tenaga kerja pada bulan itu karena stok tenaga kerja dalam keluarga masih tersisa banyak.

Selanjutnya pada dual problem solution, diketahui luas lahan masing-masing tanaman sebesar 9,95 ha, semua kendala lahan per cabang usahatani telah habis terpakai. Hal ini diindikasikan dengan kendala lahan jagung MT-1, jagung MT-2, dan kacang tanah berstatus binding atau habis terpakai tanpa ada sisa (slack). Namun sebagian kendala tidak bersifat binding hal ini terlihat pada stok tenaga kerja bulan Januari-Desember yang belum habis digunakan. Tenaga kerja yang disarankan pada bulan Januari (TKT01) adalah 424 HOK sehingga masih tersisa 498.5, tenaga kerja Februari (TKT02) 
disarankan hanya menggunakan 476,53 HOK sehingga masih tersisa 455,96 HOK. Demikian pula pada bulan Maret sampai Desember.

Produksi jagung MT-1, jagung MT-2, dan kacang tanah menunjukkan status basis dengan masing-masing luas lahan 9,95 ha. Artinya bahwa dari hasil analisis sensitivitas sepanjang penerimaan usahatani PJG1, PJG2, dan PKT tidak kurang dari 0 dan sampai infinite, maka tidak akan ada perubahan penyelesaian optimal. Demikian juga yang tejadi pada PSAPI yang menunjukan status basis dengan 80 ekor dengan penerimaan sebesar Rp. 5. 542.625 / ekor. Sepanjang penerimaan ternak sapi minimal nul dan sampai infinite, maka tidak ada perubahan penyelesaian optimal.

Pada right hand side range artinya sejauh mana kondisi optimal dipengaruhi oleh perubahan kendala tertentu. Pada right hand side range menunjukkan bahwa sepanjang lahan untuk PJG1 berada tidak kurang dari 0,000002 ha dan dan tidak lebih 9.95 ha, lahan PJG2 minimum 0,0000002 ha dan maksimal 28,19 ha, dan lahan PKT di antara 0,0000002 ha (batas minumum) dan 32,45 (batas maksimun) maka kondisi optimal tidak akan berubah, sedangkan PSAPI apabila tidak kurang dari 0 ekor dan tidak lebih dari 80 ekor, maka kondisi optimal tidak akan berubah.

Berdasarkan analisis optimasi melalui metode linear programming dengan bantuan BLPXX8 terselenggara dengan optimal, hal ini terbukti dengan pendapatan maksimum sebesar Rp. 697.334.000 artinya mengalami peningakatan pendapatan sebesar Rp.1.007.350 (0,14\%), dari pendapataan aktual saat penelitiaan sebesar Rp.696.326.650.

\section{SIMPULAN DAN SARAN}

\section{Simpulan}

Pendapatan aktual yang diperoleh dari sistem usahatani terintegrasi di SIMANTRI 001, dengan pendekatan gross margin usahatani jagung MT-1, jagung MT-2, kacang tanah dan ternak sapi sebesar Rp. 696.326.650. Berdasarkan analisis optimasi melalui metode linear programming dengan bantuan BLPXX8 terselenggara dengan optimal, dengan pendapatan maksimun sebesar Rp. 697.334.000,00, artinya meningkat sebesar Rp.1.007.350,00 (0,14\%) dari pendapatan aktual (gross margin) saat penelitian sebesar Rp.696.326.650,00.

\section{Saran}

Petani SIMANTRI 001 dapat melanjutkkan semua kegiatan produksi jagung, kacang tanah dan produksi ternak, karena semua usahatani berstatus profitable (basic). Untuk dapat meningkatkan pendapatan, mengingat masih adanya tenaga kerja yang tersisa dalam kegiatan usahatani, maka petani disarankan tidak menyewa tenaga kerja dalam usahataninya Petani disarankan agar lebih memanfaatkan limbah dari ternak untuk tanaman dan limbah tanaman untuk ternak agar proses dari pertanian terintegrasi berjalan dengan baik dan konsep zero waste tercapai. 


\section{DAFTAR PUSTAKA}

Anonim. 2016. Sistem Pertanian Terpadu-Model Pertanian Terpadu dalam Satu Siklus Biologi (Integrated Bio Cycle Farming). Http: www.kompasiana.com/windiartaji/sistem-pertanian-terpadu-model-pertanian terpadu-dalam-satu-siklus-biologi-integrated-bio- cycle-farming. diakses tanggal 25 Desember 2019.

Antara, M dan Nyoman Suardika. 2014. Optimalisasi Alokasi Sumberdaya pada Sistem Usahatani Lahan Kering di Desa Kerta Kecamatan Gianyar. Jurnal. Bali. Program Studi Agribisnis, Fakultas Pertanian, Universitas Udayana.

Agus,I G. 2013. "Efektivitas Penerapan Simantri dan Pengaruhnya Terhadap Peningkatan Pendapatan Petani-Peternak di Bali” (Disertasi). Program Studi Ilmu Peteranakan Universitas Udayana.

Arga. 1999. Program Linier. Diktat Jurusan Sosial Ekonomi Pertanian Fakultas Pertanian. Denpasar. Universitas Udayana.

Barlow, C., S. Jayasuriya, V. Cordova, L. Yambo, C. Bantilan, C. Maranan and N. Roxas, 1977. On Measuring The Ecoomic Benefits of New Technologies to Small Rice Farmers. IRRI paper: 1-49

Budiasa, I W. 2010. Pendekatan Sistem Usahatani dan Model-model Pertanian Berkelanjutan. Bahan Ajar Usahatani PS Magister Pertanian Lahan Kering. Denpasar: Program Pascasarjana Universitas Udayana,

Budiasa. I W. 2011. Pertanian Berkelanjutan. Teori dan Pemodelan. Denpasar. Udayana University Press.

Bagas, A Tarmizi; Uthuruva, T. 2015. Sistem Pertanian Terpadu. www. academia.edu/8621874/Sistem Pertanian Terpadu.

Dinas Tanaman Pangan, Hortikultura dan Perkebunan Bali. 2018. Panduan Simantri (Sistem PertanianTerintegrasi. Pemerintah Provinsi Bali.

Novitasari. 2018. “Analisis Pendapatan Diversifikasi Usahatani Padi Dan Ternak Itik Pedaging Serta Faktor-Faktor Yang Mempengaruhi Produksi Ternak Itik Pedaging Di Kabupaten Pringsewu" (Skripsi). Program Studi Agribisnis Universitas Lampung.

Demanhuri et al. 2017. Pengembangan Diversifikasi Usaha Tani Sebagai Penguatan Ekonomi Di Kabupaten Bojonegoro, Tulungagung, Dan Ponorogo. Volume 11 No. 1 Juni 2017. Hal 37-47.

Fachrudin, L. 2000. Budidaya Kacang-Kacangan. Kanisus. Yogyakarta.

Fatah, H. L. 2007. Dinamika Pembangunan Pertanian dan Pedesaan. Banjarbaru Kalsel: Pustaka Banua. 
Gonzales, C.M., 1983. Simplified and Linear Programming in Evaluating Cropping Patterns. IRRI paper: 176-187.

Herjanto, Eddy. 2008. Manajemen Operasi Edisi 3. Jakarta: Grasindo

Kariada, et al. 2002. Laporan Akhir Pengkajian Sistem Usaha Tani Integrasi Ternak Sapi Potong dan Sayuran pada FSZ Lahan Kering Dataran Tinggi Beriklim Basah. BPTP. Bali.

Kuncoro, M. 2003. Metode Riset untuk Bisnis dan Ekonomi. Bagaimana Meneliti dan Menulis Tesis. PT Gelora Aksara Pratama.

Lestari, AD. 2006. "Analisis Optimalisasi Pola Tanam Sayuran Organik di Desa Sukagalih, Kecamatan Megamendung, Kabupaten Bogor" (skripsi). Bogor: Fakultas Pertanian, Institut Pertanian Bogor.

Mubyarto. 1989. Pengantar Ekonomi Pertanian. Lembaga Pendidikan dan Penerangan Ekonomi Dan Sosial. Jakarta: PT. Gramedia Pustaka Utama

Mubyarto. 1991. Pengantar Ekonomi Pertanian. LP3ES, Jakarta.

Matheus et al. 2019. Pertanian Terpadu : Model Rancangbangun dan Penerapan pada zona agrosistem lahan kering. Sleman. CV Budi Utama.

Mudakir B. 2011. Produktivitas Lahan dan Distribusi Pendapatan Berdasarakan Status Pengunaan Lahan Usahatani Padi. Jurnal Dinamika Ekonomi Pembangunan, Vol. 1, No 1.

Nesendi dan Anwar. 1985. Program Linier dan Variasinya. Jakarta: Gramedia.

Nur'safara, Ulvinda M. 2015.’Optimasi Produksi dengan Menggunakan Metode Grafis untuk Menentukan Jumlah Produk yang Optimal (Kasus pada House of Leather Bandung)"(Skripsi). Bandung. Universitas Islam Bandung.

Siswanto. 2007. Operation Research. Jakarta: Erlangga

Soekartawi. 1993. Prinsip Dasar Ekonomi Pertanian, Teori dan Aplikasinya. Jakarta: Rajawali.

Soekartawi. 1995. Analisis Usahatani. UI Press. Jakarta

Soekartawi. 2010. Agribisnis: Teori dan Aplikasinya. Jakarta: Rajawali.

Suratiyah.2015. Ilmu Usahatani. (edisi revisi). Jakarta. Penebar Swadaya

Suharsimi. 2006. Manajemen Penelitian. Jakarta ; PT. Rineka Cipta.

Sukanteri. 2013. "Pemodelan Sistem Pertanian Terintegrasi Pendekatan: Programasi Linier (tesis)". Denpasar : Universitas Udayana. 
Taha, H.A. 1996. Riset Operasi, Suatu Pengantar (Terjemahan). Penerbit Binarupa Aksara.

Yulipriyanto,T.1997. Penerapan sistem pertanian terpadu dalam rangka pelestarian produksi menuju swasembada pangan berkelanjutan. Cakrawala pendidikan,No. 1 Tahun XVI .Februari 1997.

Yuni Embriana D U. (2015). "Efektivitas Penyelesaian Model Nonlinear Menggunakan Pendekatan Quadratic Programming dan Separable Programming Untuk Optimasi Biaya Produksi Pada Industri Bakpia 716" (skripsi) . Yogyakarta: FMIPA Universitas Negeri Yogyakarta.

Wanda, F.A. 2015. Analisis Pendapatan Usahatani Jeruk Siam: Studi Kasus di Desa Padang Parangrapat Kecamatan Tanah Grogot Kabupaten Paser. eJournal Administrasi Bisnis, Vol. 3, No. 3, hlm. 600-611.

Winston, W.L. 1994. Operation research : applications and algorithms. Third Edition. 